\title{
ETNOMATEMATIKA: EKSPLORASI PEMBUATAN TAHU KHAS KALISARI KABUPATEN BANYUMAS SEBAGAI SUMBER PEMBELAJARAN MATEMATIKA
}

\author{
Fitria Zana Kumala \\ Tadris Matematika UIN Prof. K.H. Saifuddin Zuhri Purwokerto \\ Email: fitriazana@uinsaizu.ac.id
}

\begin{abstract}
Abstrak. Pembelajaran matematika di sekolah seringkali tidak kontekstual dan dikaitkan dengan budaya karena matematika dianggap tidak ada kaitannya dengan budaya yang ada. Sebagai kabupaten yang kaya akan budaya, pendidik di Kabupaten Banyumas dapat mengintegrasikan kekayaan budaya tersebut dalam pembelajaran matematika. Salah satu kekayaan budaya tersebut adalah berupa makanan khas yang terdapat di Kabupaten Banyumas. Tahu Kalisari merupakan produk tahu Kabupaten Banyumas yang memiliki cita rasa khas dan bentuk geometri yang beragam. Masyarakat Desa Kalisari yang mayoritas berprofesi sebagai pembuat tahu tanpa disadari telah menerapkan konsep-konsep matematika dalam proses pembuatan tahu khas Kalisari. Penelitian ini bertujuan untuk mengeksplorasi aktivitas yang melibatkan konsep-konsep matematika yang terdapat dalam proses pembuatan tahu khas Kalisari.Penelitian ini merupakan penelitian deskriptif kualitatif yang menggunakan pendekatan etnografi. Observasi, dokumentasi dan wawancara dengan pembuat tahu khas Kalisari digunakan sebagai teknik pengumpulan data. Penelitian ini menunjukkan bahwa pembuatan tahu khas kalisari melibatkan konsep-konsep matematika yaitu konsep geometri berupa bangun datar dua dimensi (persegi, persegi panjang) dan bangun ruang tiga dimensi (tabung tanpa tutup, setengah bola, balok, balok tanpa alas dan tutup, balok tanpa tutup, limas segiempat, dan bola), konsep pembagian, perbandingan senilai, dan kekongruenan yang dapat digunakan sebagai sumber pembelajaran matematika yang kontekstual.
\end{abstract}

\section{Kata Kunci: Etnomatematika, Tahu Khas Kalisari, Geometri, Pembagian, Perbandingan Senilai, Kekongruenan}

\begin{abstract}
Mathematics learning at schools is often not contextual and culturally related because mathematics is considered to have nothing to do with the existing culture. As a district that is rich in culture, educators in Banyumas Regency can integrate the cultural wealth in learning mathematics. One of the cultural treasures is in the form of special foods found in Banyumas Regency. Kalisari tofu is a tofu product from Banyumas Regency which has a distinctive taste and various geometric shapes. Kalisari village community which majority of whom work as tofu makers, without realising actually applied mathematical concepts in the process of making special Kalisari tofu. This study aims to explore activities that involve mathematical concepts contained in the process of making special Kalisari tofu. This research is a qualitative descriptive study that uses an ethnographic approach. Observation, documentation and interview with Kalisari tofu makers are used as data collection techniques. This study shows that the production of special Kalisari tofu involves mathematical concepts, namely the concept of geometry in the form of two-dimensional flat shapes (square, rectangle) and a constructed three-dimensional shapes (tube without lid, hemispherical, block, block without base and lids, blocks without lids, rectangular pyramids, and spheres), concepts of division, direct proportion and congruence that can be used as a source of contextual mathematics learning.
\end{abstract}

Keywords: Ethnomathematics, Special Kalisari Tofu, Geometry, Division, Direct Proportion, Congruence

\section{A. Pendahuluan}

Hasil studi Programme for International Student Assessment (PISA) pada tahun 2018 yang dirilis pada tahun 2019 menyatakan bahwa skor matematika Indonesia berada di peringkat 72 dari 78 negara (Harususilo, 2019). Matematika masih dianggap sebagai mata pelajaran yang sulit oleh peserta didik, namun penting untuk dipelajari (Siregar, 2017). Persepsi negatif mengenai matematika ada karena matematika dianggap sebagai sesuatu yang abstrak, kering, dan teoritis. Padahal, berbagai disiplin ilmu dapat didalami dengan baik jika peserta didik memiliki kemampuan dalam mata pelajaran matematika (Kamarullah, 2017). 
Salah satu hal yang dapat dilakukan oleh pendidik matematika untuk menghilangkan persepsi negatif peserta didik terhadap matematika pada saat sekarang ini adalah menyelenggarakan pembelajaran matematika yang kontekstual dengan sumber pembelajaran yang berasal dari lingkungan sekitar. Sumber pembelajaran kontekstual yang dapat dimanfaatkan oleh pendidik salah satunya adalah kebudayaan lokal. Pendidik matematika dapat berinovasi dengan menyelenggarakan pembelajaran matematika berbasis budaya lokal (Pathuddin \& Raehana, 2019). Etnomatematika merupakan studi yang menjelaskan tentang hubungan antara matematika dan budaya (Pathuddin et al., 2021). Sebagai jembatan antara matematika dan budaya, etnomatematika dapat memberikan pengetahuan yang lebih mudah untuk dipahami karena menggunakan tradisi setempat dalam pembelajaran matematika (Putri, 2017).

Penelitian terdahulu yang berkaitan dengan etnomatematika diantaranya adalah penelitian yang dilakukan oleh (Nisa, 2020) yang memberikan kesimpulan bahwa terdapat konsep-konsep matematika yang terdapat dalam batik Pamiluto Gresik yaitu konsep titik, garis, dan lain lain yang dapat dimanfaatkan sebagai media pembelajaran. Selanjutnya penelitian yang dilakukan oleh (Putri, 2017) yang mengeksplorasi rebana sebagai sumber belajar matematika. Penelitian mengenai etnomatematika pada candi Borobudur dilakukan oleh (Utami et al., 2020). Etnomatematika pada permainan dengklaq diteliti oleh (Fauzi \& Lu'luilmaknun, 2019) dan memberikan kesimpulan bahwa permainan dengklaq dapat digunakan sebagai media pembelajaran matematika. Etnomatematika pada kesenian calung Banyumas diteliti oleh (Ayu, 2020) yang memberikan kesimpulan bahwa terdapat konsep-konsep matematika yang dapat ditemukan yaitu konsep tabung dan titik pusat lingkaran.

Berdasarkan penelitian yang sudah dilakukan, masih sedikit penelitian yang mengeksplorasi konsep matematika pada kekayaan budaya Banyumas. Kabupaten Banyumas merupakan kabupaten yang sangat kaya akan budaya, dimana salah satunya adalah makanan khas berupa tahu Kalisari yang sudah terkenal kelezatannya dan beraneka macam bentuk geometrinya. Kepopuleran tahu Kalisari pada masyarakat Kabupaten Banyumas tersebut dapat menjadi modal bagi pendidik untuk mengeksplorasi dan menjadikannya sebagai sumber pembelajaran konstektual dan menjadikan pembelajaran matematika yang bermakna. Berdasarkan latar belakang tersebut peneliti tertarik untuk melakukan penelitian yang berkaitan dengan eksplorasi pembuatan tahu khas Kalisari Kabupaten Banyumas yang melibatkan konsep-konsep matematika yang dapat dijadikan sebagai sumber pembelajaran matematika.

\section{B. Metodologi Penelitian}

Penelitian ini merupakan penelitian deskriptif kualitatif dengan pendekatan etnografi. Tujuan dari penelitian ini adalah untuk mengungkapkan etnomatematika pada aktivitas pembuatan tahu khas kalisari Kabupaten Banyumas. Desain penelitian ini menggunakan kerangka studi etnomatematika yang dikembangkan melalui empat pertanyaan umum, yaitu "dimana mencarinya?", "bagaimana mencarinya?", "apa ini?", dan "apa artinya?" (Pathuddin et al., 2021; Prahmana \& D’Ambrosio, 2020). Desain penelitian tersaji pada Tabel 1.

Selanjutnya, observasi dan dokumentasi pembuatan tahu khas Kalisari serta wawancara dengan delapan orang pembuat tahu khas Kalisari digunakan sebagai teknik pengumpulan data. Pemilihan delapan orang pembuat tahu khas Kalisari tersebut menggunakan purposive dan snowball sampling. Objek yang diobservasi adalah bahan, alat, dan tahapan pembuatan tahu khas kalisari. Data yang diperoleh dari observasi, dokumentasi, dan wawancara dianalisisis dengan metode triangulasi untuk mengeksplorasi hubungan antara aktivitas pembuatan tahu khas Kalisari dengan konsep-konsep matematika.

Tabel 1. Desain Penelitian 


\begin{tabular}{|c|c|c|}
\hline $\begin{array}{c}\text { Pertanyaan } \\
\text { Umum }\end{array}$ & Jawaban Awal & Aktifitas Spesifik \\
\hline Dimana mencarinya & $\begin{array}{l}\text { Pada aktivitas pembuatan tahu khas Budaya } \\
\text { Kalisari dimana terdapat praktik } \\
\text { matematika didalamnya }\end{array}$ & $\begin{array}{l}\text { Wawancara dengan } \\
\text { pembuat tahu khas Kalisari }\end{array}$ \\
\hline $\begin{array}{l}\text { Bagaimana } \\
\text { mencarinya }\end{array}$ & $\begin{array}{l}\text { Menginvestigasi aspek QRS Pemikiran Alternatif } \\
\text { (Qualitative, Relational, and Spatial) } \\
\text { pada pembuatan tahu khas Kalisari } \\
\text { dihubungkan dengan konsep-konsep } \\
\text { matematika }\end{array}$ & $\begin{array}{l}\text { Menentukan ide QRS yang } \\
\text { terkandung pada pembuatan } \\
\text { tahu khas Kalisari } \\
\text { dihubungkan dengan } \\
\text { konsep-konsep matematika }\end{array}$ \\
\hline Apa ini & Filosofi Matematika & $\begin{array}{l}\text { Mengidentifikasi } \\
\text { karakteristik QRS pada } \\
\text { proses pembuatan tahu khas } \\
\text { Kalisari }\end{array}$ \\
\hline Apa artinya & $\begin{array}{l}\text { Nilai budaya dan matematika yang Antropologi } \\
\text { signifikan }\end{array}$ & $\begin{array}{l}\text { Mendeskripsikan konsep- } \\
\text { konsep matematika pada } \\
\text { proses pembuatan tahu khas } \\
\text { Kalisari }\end{array}$ \\
\hline
\end{tabular}

\section{Hasil Penelitian dan Pembahasan}

Pada penelitian ini, etnomatematika difokuskan pada pembuatan tahu khas Kalisari yang dilakukan oleh pembuat tahu di Desa Kalisari Kecamatan Cilongok Kabupaten Banyumas. Deskripsi etnomatematika dideskripsikan melalui wawancara dengan pembuat tahu khas Kalisari yang kemudian dikonfirmasi melalui observasi langsung pada proses pembuatan tahu khas Kalisari dan melalui dokumentasi sebagai data pendukung. Konsep-konsep matematika yang diperoleh dari hasil penelitian ini adalah konsep geometri berupa bangun datar dua dimensi (persegi, persegi panjang) dan bangun ruang tiga dimensi (tabung tanpa tutup, setengah bola, balok, balok tanpa alas dan tutup, balok tanpa tutup, limas segi empat, dan bola), konsep pembagian, perbandingan senilai dan kongruensi.

\section{Konsep Geometri (Bangun Datar Dua Dimensi dan Bangun Ruang Tiga Dimensi)}

\section{Dialog 1}

Peneliti : Apa yang harus dilakukan pertama kali dalam pembuatan tahu khas Kalisari?

Pembuat tahu : Rendam kedelai dalam ember sehari semalam, setelah itu kedelai dicuci hingga bersih

Peneliti : Bagaimana selanjutnya?

Pembuat tahu : Giling kedelai dengan air sampai menjadi bubur kedelai, kemudian masukkan ke dalam ember untuk selanjutnya direbus di dalam tungku (sembari menunjukkan tungku berbentuk tabung tanpa tutup yang di dalamnya sekaligus terdapat wajan yang terbuat dari besi yang berbentuk setengah bola)

Peneliti : Direbusnya setelah menjadi bubur, bukan ketika masih menjadi kedelai utuh?

Pembuat tahu : Ya, setelah menjadi bubur kedelai direbus di dalam tungku selama satu jam

Peneliti : Selanjutnya?

Pembuat tahu: Saring dengan kain (berbentuk persegi panjang) agar terpisah antara sari kedelai dengan ampasnya

Peneliti : Ampasnya dibuang?

Pembuat tahu : Di-press terlebih dahulu sampai sari dalam ampas habis

Peneliti : Selanjutnya apa lagi?

Pembuat tahu : Selanjutnya itu "nglaru"

Peneliti : "Nglaru" itu apa? 
Pembuat tahu : "Nglaru" artinya menambahkan air laru ke dalam sari, aduk sampai air laru dan sari tercampur, tunggu selama lima belas menit sampai terbentuk bubur tahu

Peneliti : Air laru itu apa?

Pembuat tahu : Air laru adalah air sisa pembuatan tahu hari kemarin. Setelah terbentuk bubur tahu, sari akan terpisah menjari dua, bubur tahu dan air. Air itulah yang disebut air laru, yang akan digunakan pada proses pembuatan tahu selanjutnya

Peneliti : Selanjutnya bubur tahu yang terbentuk diapakan?

Pembuat tahu : Bubur tahu selanjutnya dicetak dan di-press untuk mengurangi kandungan air (sembari menunjukkan alat cetak tahu yang terbuat dari kayu yang berukuran panjang $40 \mathrm{~cm}$, lebar $55 \mathrm{~cm}$, dan tinggi $8 \mathrm{~cm}$ ). Tinggi tahu yang dibuat menyesuaikan harga kedelai.

Peneliti : Setelah bubur tahu dicetak dan di-press, selanjutnya bagaimana?

Pembuat tahu : Sudah terbentuk tahu, tinggal dibagi sesuai ukuran.

Peneliti : Bagaimana cara membagi tahu tersebut?

Pembuat tahu : Tahu yang telah dicetak dipotong dengan pisau menggunakan alat bantu untuk meluruskan hasil potongan (sembari menunjukkan alat bantu yang terbuat dari kayu berbentuk balok dengan panjang $70 \mathrm{~cm}$, lebar $5 \mathrm{~cm}$, dan tinggi $1 \mathrm{~cm}$ )

Peneliti : Setelah tahu dipotong-potong sesuai ukuran, apakah sudah selesai?

Pembuat tahu : Belum, tahu tersebut dibungkus dengan menggunakan kain (sembari menunjukkan kain berbentuk persegi berukuran $18 \mathrm{~cm} \times 18 \mathrm{~cm}$ ) dan di-press lagi agar air dalam tahu semakin menyusut

Peneliti : Setelah di-press, tahu sudah jadi?

Pembuat tahu : Ya. Lepaskan kain pembungkus tersebut. Sudah selesai proses pembuatan tahu putih

Dialog 1 pada penelitian ini mengungkapkan tahapan pembuatan tahu khas kalisari dimulai dari perendaman kedelai sampai selesai proses pembuatan tahu, yaitu proses press akhir tahu dan pelepasan kain pembungkus tahu. Bahan yang dibutuhkan pada proses tersebut hanya kedelai dan air. Alat yang digunakan oleh pembuat tahu khas Kalisari pada tahapan yang melibatkan konsep geometri tersaji pada Tabel 2.

Dialog 2

Peneliti : Selain bentuk Balok, apakah ada bentuk lain dari tahu khas Kalisari?

Pembuat tahu : Ya. terdapat bentuk lain (sembari menunjukkan tahu yang berbentuk limas segi empat)

Peneliti : Apakah alat yang digunakan untuk membentuk tahu yang berbentuk limas segiempat tersebut sama dengan alat yang digunakan untuk membentuk tahu yang berbentuk balok?

Pembuat tahu : Ya, sama. Jika akan membentuk tahu yang berbentuk ini (sambil menunjukkan tahu yang berbentuk limas segi empat) maka tahu yang ini (sambil menunjukkan tahu yang berbentuk balok) dibagi dua (sambil mempraktekkan pemotongan pada salah satu diagonalnya).

Dialog 2 pada penelitian ini mengungkapkan bahwa selain tahu yang berbentuk balok, pembuat tahu khas Kalisari juga ada yang membuat tahu yang berbentuk limas segi empat. Alat yang digunakan oleh pembuat tahu khas Kalisari untuk memotong tahu yang berbentuk limas segi empat tersebut sama dengan alat yang digunakan untuk membentuk tahu yang berbentuk balok. Konsep geometri tersebut tersaji pada Tabel 2. 
Dialog 3

Peneliti

: Selain tahu yang berbentuk balok dan limas segi empat, adakah bentuk geometri lain dari tahu khas Kalisari?

Pembuat tahu : Ya. sebagai bentuk inovasi yang terus dilakukan oleh pembuat tahu khas Kalisari, maka dibuat tahu bolo-bolo yang sudah memiliki banyak penggemar

Peneliti : Apa itu tahu bolo-bolo?

Pembuat tahu : Tahu bolo-bolo adalah tahu putih yang dihancurkan dan ditambah dengan bumbu-bumbu yang kemudian dibentuk bola-bola tahu kecil dan digoreng.

Dialog 3 pada penelitian ini mengungkapkan bahwa selain tahu yang berbentuk balok dan limas segi empat, pembuat tahu khas Kalisari berinovasi dengan membuat tahu bolo-bolo yang berbentuk bola. Alat yang digunakan oleh pembuat tahu khas Kalisari untuk membentuk tahu bolo-bolo yang berbentuk bola tersebut berbeda dengan alat yang digunakan untuk membentuk tahu yang berbentuk balok dan limas segi empat, dimana untuk membuat bulatan tahu bolobolo digunakan tangan saja, tidak menggunakan pisau dan alat bantu yang terbuat dari kayu. Konsep geometri tersebut tersaji pada Tabel 2.

Tabel 2. Konsep Matematika pada Tahapan Pembuatan Tahu khas Kalisari

Tahapan Pembuatan Tahu Khas Kalisari $\quad$ Konsep Matematika

Gambar 1. Perendaman Kedelai

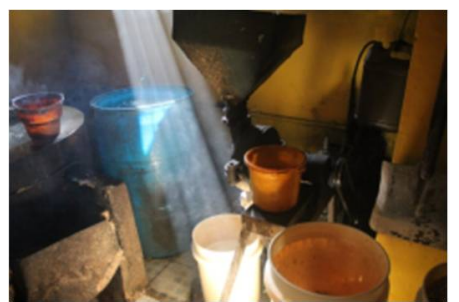

Gambar 3. Penggilingan Kedelai

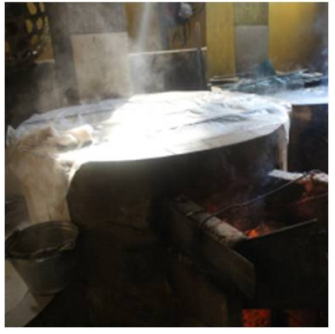

Gambar 4. Perebusan Bubur Kedelai

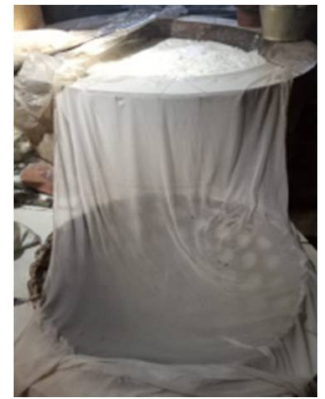

Gambar 6. Penyaringan Bubur Kedelai
Gambar 2. Tabung Tanpa Tutup

Tabung tanpa tutup

Gambar 2

Tabung tanpa tutup dan setengah bola

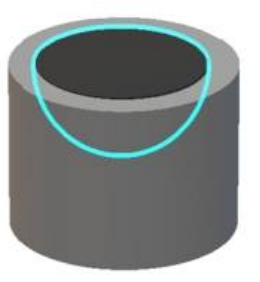

Gambar 5. Tabung Tanpa Tutup dan Setengah Bola

Gambar 5

Tabung tanpa tutup dan setengah bola, persegi panjang

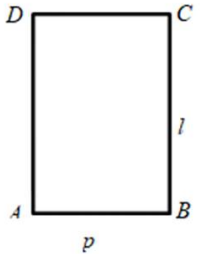

Gambar 7. Persegi Panjang 


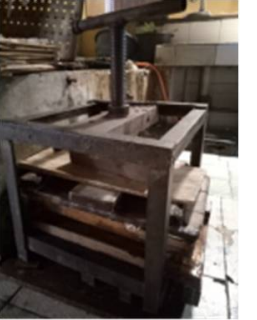

Gambar 8. Proses press Bubur Kedelai

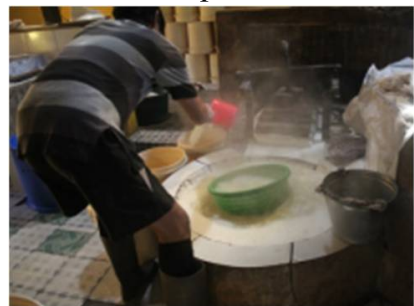

Gambar 9. Proses "nglaru”

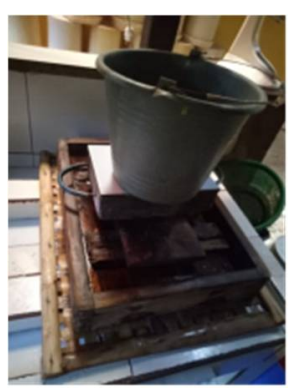

Gambar 10. Pencetakan dan Proses press Bubur Tahu
Persegi panjang

Tabung tanpa tutup dan setengah bola
Gambar 2

Gambar 5

\section{Balok, balok tanpa alas dan tutup, persegi panjang}

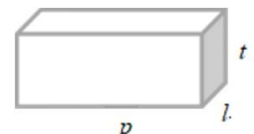

Gambar 11. Balok

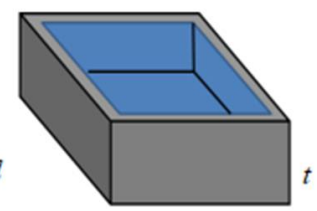

$$
p
$$

Gambar 12. Balok Tanpa Alas dan Tutup

Gambar 7

Persegi panjang, balok

Gambar 13. Pemotongan Tahu Berbentuk Balok

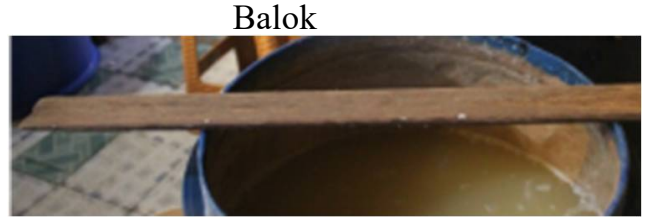

Gambar 14. Alat Bantu Pemotongan Tahu

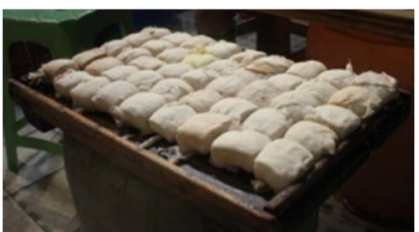

Gambar 15. Pembungkusan Tahu
Balok tanpa tutup, persegi

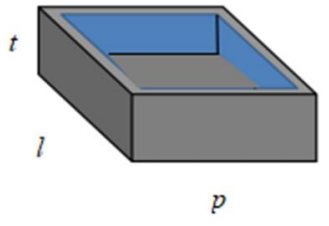

Gambar 16. Balok Tanpa Tutup 


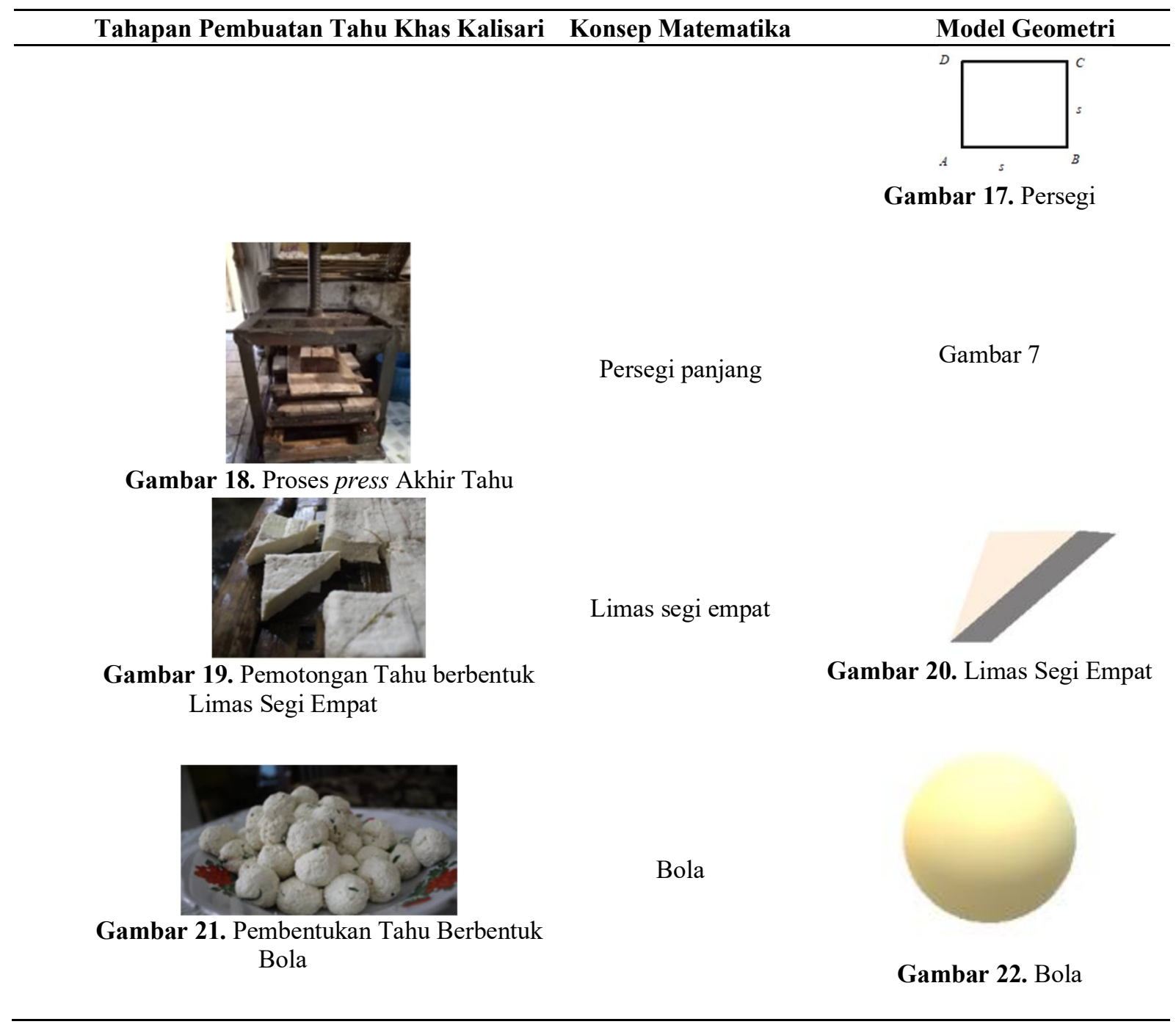

\section{Konsep Pembagian}

Dari cetakan tahu pada Gambar 7, jika dicetak tahu dengan ukuran $40 \mathrm{~cm} \times 55 \mathrm{~cm} \times 2$ $\mathrm{cm}$ maka volume tahu yang terbentuk tersebut adalah $40 \mathrm{~cm} \times 55 \mathrm{~cm} \times 2 \mathrm{~cm}=4400 \mathrm{~cm}^{3}$. Dengan menggunakan alat bantu untuk meluruskan hasil potongan yang terbuat dari kayu yang berukuran lebar $5 \mathrm{~cm}$, maka setiap tahu yang terpotong akan berbentuk balok yang memiliki volume sebesar $5 \mathrm{~cm} \times 5 \mathrm{~cm} \times 2 \mathrm{~cm}=50 \mathrm{~cm}^{3}$ sehingga setiap cetakan tahu tersebut akan menghasilkan tahu sebanyak $\frac{4400 \mathrm{~cm}^{3}}{50 \mathrm{~cm}^{3}}=88$ buah tahu.

Selanjutnya, karena tahu berukuran $5 \mathrm{~cm} \times 5 \mathrm{~cm} \times 2 \mathrm{~cm}$ yang dihasilkan dari setiap cetakan tahu adalah sebanyak 88 buah maka tahu berbentuk limas segi empat yang diperoleh dengan membagi tahu berukuran $5 \mathrm{~cm} \times 5 \mathrm{~cm} \times 2 \mathrm{~cm}$ tersebut menjadi dua sama besar adalah sebanyak $\frac{88}{\frac{1}{2}}=176$ buah tahu.

Selanjutnya, jika akan dibuat tahu bolo-bolo dari tahu putih yang berbentuk balok dengan ukuran $5 \mathrm{~cm} .5 \mathrm{~cm} .2 \mathrm{~cm}$ sebanyak 20 buah, maka total volume tahu adalah $5 \mathrm{~cm} \times 5 \mathrm{~cm} \times 2 \mathrm{~cm}$ $\times 20=1000 \mathrm{~cm}^{3}$. Jika akan dibentuk tahu bolo-bolo sebanyak 125 buah dari total volume tahu tersebut maka masing-masing tahu bolo-bolo akan memiliki volume sebesar $\frac{1000 \mathrm{~cm}^{3}}{125}=8 \mathrm{~cm}^{3}$, sehingga masing-masing tahu bolo-bolo tersebut akan memiliki jari-jari sebesar $\frac{4}{3} \pi r^{3}=$ $8 \mathrm{~cm}^{3} \Leftrightarrow \frac{4}{3} 3.14 r^{3}=8 \mathrm{~cm}^{3} \Leftrightarrow r=\sqrt[3]{\frac{8}{\frac{4}{3} 3.14}} \approx 1.24 \mathrm{~cm}$. 


\section{Konsep Perbandingan Senilai}

Dari cetakan tahu pada Gambar 7 dapat terbentuk tahu yang berbentuk balok berukuran $5 \mathrm{~cm}$ $\times 5 \mathrm{~cm} \times 2 \mathrm{~cm}$ sebanyak 88 buah tahu. Jika dalam sehari pembuat tahu dapat mencetak tahu sebanyak 60 cetakan maka dalam sehari pembuat tahu tersebut dapat membuat $\frac{1}{88}=\frac{60}{x} \Leftrightarrow x=$ $88.60=5280$ buah tahu yang berbentuk balok berukuran $5 \mathrm{~cm} \times 5 \mathrm{~cm} \times 2 \mathrm{~cm}$.

\section{Konsep Kekongruenan}

Pada gambar 8 terlihat bahwa tahu yang telah dipotong-potong dari sebuah cetakan tahu adalah sejumlah 88 tahu yang berukuran $5 \mathrm{~cm} \times 5 \mathrm{~cm} \times 2 \mathrm{~cm}$ yang memiliki sisi berupa persegi dan persegi panjang yang berukuran $5 \mathrm{~cm} \times 5 \mathrm{~cm}$ dan $5 \mathrm{~cm} \times 2 \mathrm{~cm}$. Persegi-persegi yang terbentuk tersebut kongruen. Selanjutnya, persegi panjang-persegi panjang yang terbentuk tersebut juga kongruen.
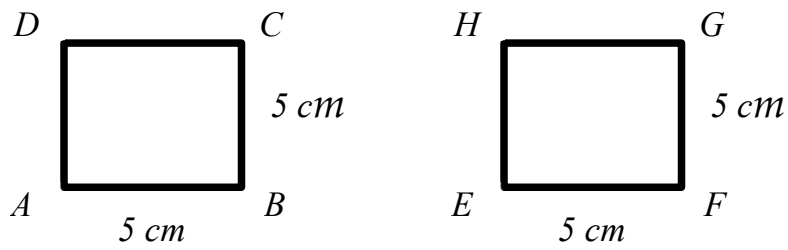

Gambar 23. Konsep Kekongruenan pada Persegi
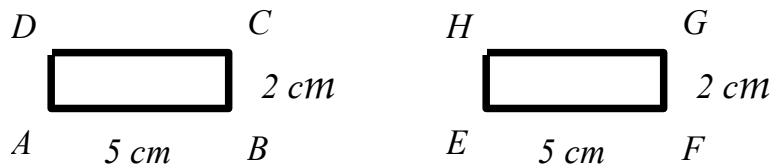

Gambar 24. Konsep Kekongruenan pada Persegi Panjang

Sudut-sudut yang bersesuaian sama besar
$\angle A=\angle E$
$\angle D=\angle H$
$\angle B=\angle F$
$\angle C=\angle G$

Sisi-sisi yang bersesuaian sama panjang
$A B=E F$
$A D=E H$
$C D=G H$
$B C=F G$

\section{Tahu Khas Kalisari Kabupaten Banyumas sebagai Masalah Kontekstual dalam Pembelajaran Matematika}

Proses pembuatan tahu khas Kalisari Kabupaten Banyumas dapat digunakan sebagai masalah kontekstual yang dapat dikembangkan kepada peserta didik dalam pembelajaran matematika. Masalah kontekstual tersebut dapat memberikan kesempatan bagi peserta didik untuk memecahkan masalah-masalah yang berkaitan dengan dunia nyata sehingga dimungkinkan dapat diperoleh pemahaman yang komprehensif (Pathuddin et al., 2021). Proses pembuatan tahu khas Kalisari beserta konsep-konsep matematika dalam tahapan pembuatan tahu khas Kalisari dapat dijelaskan oleh pendidik. Contoh pembelajaran berbasis budaya lokal khususnya dalam proses pembuatan makanan khas berupa tahu khas Kalisari Kabupaten Banyumas yang dapat digunakan dalam pembelajaran matematika adalah sebagai berikut.

1. Konsep Geometri

Berdasarkan hasil penelitian diketahui bahwa pada proses perendaman kedelai dapat digunakan ember yang berbentuk tabung tanpa tutup. Pendidik dapat menjelaskan proses awal pembuatan tahu yaitu dengan melakukan perendaman kedelai selama sehari semalam. 
Selanjutnya pendidik dapat berdiskusi mengenai apa saja bahan yang digunakan dalam proses perendaman kedelai. Selanjutnya, pendidik juga dapat menjelaskan proses perebusan bubur kedelai oleh pembuat tahu khas Kalisari dapat menggunakan tungku berbentuk tabung yang di dalamnya terdapat wajan yang berbentuk setengah bola yang terbuat dari besi. Pendidik dapat mengajukan pertanyaan kepada peserta didik sebagai berikut.

a. Pak Ahmad adalah seorang pembuat tahu khas Kalisari yang akan membuat tahu dari $100 \mathrm{~kg}$ kedelai dalam sehari. Jika ia merendam kedelai dalam ember bekas cat yang berdiameter $30 \mathrm{~cm}$ dan tinggi $40 \mathrm{~cm}$, dan setiap ember diisi kedelai hanya 3/4 bagian saja, berapa buah ember yang berukuran sama yang dibutuhkan oleh Pak Ahmad untuk merendam $100 \mathrm{~kg}$ kedelai tersebut?

b. Jika Pak Ahmad akan merebus kedelai dalam wajan yang berbentuk setengah bola yang terbuat dari besi yang berdiameter $80 \mathrm{~cm}$ dan wajan tersebut hanya diisi 3/4 dari kapasitas wajan, berapa volume bubur kedelai yang direbus Pak Ahmad dalam sekali perebusan?

\section{Konsep Pembagian}

Berdasarkan hasil penelitian diketahui bahwa pada proses ke-7 dari pembuatan tahu khas Kalisari Kabupaten Banyumas adalah proses pencetakan dan proses press bubur tahu dalam cetakan yang berbentuk balok tanpa alas dan tutup sebelum tahu tersebut dipotong pada proses ke-8. Pendidik dapat mengajukan pertanyaan kepada peserta didik sebagai berikut.

a. Diketahui bahwa Pak Ahmad mencetak tahu dengan ukuran $40 \mathrm{~cm} \times 55 \mathrm{~cm} \times 3 \mathrm{~cm}$ dengan menggunakan cetakan. Berapa jumlah tahu yang didapatkan oleh Pak Ahmad dari satu cetakan tersebut jika tahu akan dipotong berbentuk balok yang memiliki ukuran $2 \mathrm{~cm} \times 5 \mathrm{~cm} \times 3 \mathrm{~cm}$ ?

b. Berapa jumlah tahu yang berukuran limas segi empat yang dapat diperoleh jika tahu dengan ukuran $2 \mathrm{~cm} \times 5 \mathrm{~cm} \times 3 \mathrm{~cm}$ pada poin a dibagi menjadi dua sama besar pada salah satu diagonalnya?

\section{Konsep Perbandingan Senilai}

Pendidik dapat menjelaskan bahwa semakin banyak kedelai yang digunakan untuk membuat tahu maka pencetakan bubur kedelai dengan menggunakan cetakan akan semakin banyak sehingga pada akhirnya semakin banyak pula jumlah tahu yang akan didapatkan, begitu juga sebaliknya. Pendidik dapat mengajukan pertanyaan kepada peserta didik sebagai berikut.

a. Jika satu kali perebusan bubur kedelai pada wajan yang berbentuk setengah bola berdiameter $80 \mathrm{~cm}$ membutuhkan waktu satu jam, berapa lama total waktu yang dibutuhkan Pak Ahmad untuk merebus bubur kedelai jika dilakukan perebusan sebanyak 10 kali?

b. Pak Ahmad memotong tahu yang telah tercetak dengan ukuran $40 \mathrm{~cm} \times 55 \mathrm{~cm} \times 2$ $\mathrm{cm}$ menjadi tahu yang berbentuk balok yang berukuran $5 \mathrm{~cm} \times 5 \mathrm{~cm} \times 2 \mathrm{~cm}$ maka didapatkan 88 buah tahu. Jika pak Ahmad mencetak 60 kali dengan menggunakan cetakan tersebut, berapa jumlah tahu yang didapatkan oleh Pak Ahmad?

\section{Konsep Kekongruenan}

Pendidik dapat menjelaskan kepada peserta didik bahwa sisi permukaan tahu yang telah dipotong-potong yang kongruen jika tahu dipotong dengan ukuran yang sama persis baik sudutnya maupun panjang sisinya. Pendidik dapat memberikan tugas kepada siswa sebagai berikut.

a. Selain yang telah dijelaskan, sebutkan penerapan konsep kekongruenan yang termuat pada proses pembuatan tahu khas Kalisari Kabupaten Banyumas!

b. Jelaskan mengenai syarat kekongruenan dari jawaban anda pada poin a!

Hasil dari penelitian ini menunjukkan bahwa terdapat konsep-konsep matematika yang termuat dalam proses pembuatan tahu khas Kalisari. Hal tersebut sejalan dengan tujuan 
etnomatematika untuk mendekatkan matematika kepada realitas dan persepsi masyarakat (Pathuddin et al., 2021). Etnomatematika meningkatkan minat dan motivasi peserta didik dalam mengikuti pembelajaran matematika (Fajriyah, 2018). Dengan melibatkan budaya yang ada di sekitar peserta didik maka anggapan bahwa matematika adalah mata pelajaran yang sulit dapat berubah, sehingga pada akhirnya minat dan hasil belajar peserta didik dapat meningkat (Pathuddin et al., 2021).

Penelitian ini sejalan dengan penelitian (Huda, 2018) yang menemukan konsep-konsep geometri bidang seperti lingkaran, elips, segitiga, segiempat, dan trapesium serta konsepkonsep geometri ruang seperti bola, tabung, balok, dan kerucut pada jajanan pasar di Daerah Istimewa Yogyakarta. Konsep bangun ruang berupa prisma segitiga serta konsep pembagian dan kekongruenan ditemukan dalam eksplorasi makanan khas Suku Bugis yaitu Kue Barongko yang digunakan sebagai sumber pembelajaran matematika (Pathuddin et al., 2021). Selain itu makanan tradisional Bugis lain yang memuat konsep matematika adalah tumpi-tumpi yang berbentuk segitiga, jompo-jompo yang berbentuk lingkaran, burasa yang berbentuk persegi panjang, onde-onde yang berbentuk bola, doko-doko yang berbentuk limas, paso yang berbentuk kerucut, dan putu coppa yang berbentuk tabung yang juga dapat digunakan sebagai sumber pembelajaran matematika yang bermakna (Pathuddin \& Raehana, 2019). Makanan khas Kota Bengkulu Bay Tat juga telah dieksplorasi oleh (Pusvita et al., 2019) untuk membantu proses pembelajaran matematika. Penelitian ini dapat digunakan sebagai pelengkap penelitian terdahulu yang sudah membahas mengenai etnomatematika pada makanan khas suatu daerah. Penelitian ini membahas etnomatematika dengan objek yang berbeda dengan penelitian terdahulu, dimana pada penelitian ini telah dibahas mengenai eksplorasi tahu khas Kalisari Kabupaten Banyumas sebagai sumber pembelajaran matematika.

\section{Kesimpulan}

Berdasarkan hasil penelitian dapat disimpulkan bahwa dengan mengeksplorasi tahu khas Kalisari sebagai makanan khas Kabupaten Banyumas dapat diketahui bahwa terdapat konsepkonsep matematika yang termuat dalam pembuatan tahu khas Kalisari. Konsep-konsep tersebut berupa konsep geometri bangun datar dua dimensi (persegi, persegi panjang) dan bangun ruang tiga dimensi (tabung tanpa tutup, setengah bola, balok, balok tanpa alas dan tutup, balok tanpa tutup, limas segi empat, dan bola), konsep pembagian, perbandingan senilai dan kongruensi yang dapat digunakan oleh pendidik matematika sebagai sumber pembelajaran matematika yang kontekstual. Dengan menggunakan tahu khas Kalisari Kabupaten Banyumas sebagai sumber pembelajaran matematika, maka proses pembelajaran matematika yang dialami oleh peserta didik akan lebih bermakna karena melibatkan sumber pembelajaran yang berasal dari kebudayaan di daerah asal peserta didik.

\section{DAFTAR PUSTAKA}

Ayu, D. S. (2020). Etnomatematika pada Kesenian Calung Banyumas. PROSIDING.

Fajriyah, E. (2018). Peran Etnomatematika Terkait Konsep Matematika dalam Mendukung Literasi. PRISMA: Prosiding Seminar Nasional Matematika, 1, 114-119. https://journal.unnes.ac.id/sju/index.php/prisma/

Fauzi, A., \& Lu'luilmaknun, U. (2019). Etnomatematika pada Permainan Dengklaq sebagai Media Pembelajaran Matematika. Aksioma: Jurnal Program Studi Pendidikan Matematika, $8(3)$, 408-419. http://www.tjyybjb.ac.cn/CN/article/downloadArticleFile.do?attachType=PDF\&id=9987 
Harususilo, Y. E. (2019). Skor PISA Terbaru Indonesia, ini 5 PR Besar Pendidikan pada Era Nadiem Makarim. https://edukasi.kompas.com/read/2019/12/04/13002801/skor-pisaterbaru-indonesia-ini-5-pr-besar-pendidikan-pada-era-nadiem-makarim?page $=$ all

Huda, N. T. (2018). Etnomatematika pada Bentuk Jajanan Pasar di Daerah Istimewa Yogyakarta. JNPM (Jurnal Nasional Pendidikan Matematika), 2(2), 217. https://doi.org/10.33603/jnpm.v2i2.870

Kamarullah, K. (2017). Pendidikan Matematika di Sekolah Kita. Al Khawarizmi: Jurnal Pendidikan Dan Pembelajaran Matematika, 1(1), 21-32. https://doi.org/10.22373/jppm.v1i1.1729

Nisa, R. (2020). Eksplorasi Etnomatematika pada Batik Pamiluto Gresik. Briliant: Jurnal Riset Dan Konseptual, 5(3), 442. https://doi.org/10.28926/briliant.v5i3.462

Pathuddin, H., Kamariah, \& Ichsan Nawawi, M. (2021). Buginese Ethnomathematics: Barongko Cake Explorations as Mathematics Learning Resources. Journal on Mathematics Education, 12(2), 295-312. https://doi.org/10.22342/jme.12.2.12695.295312

Pathuddin, H., \& Raehana, S. (2019). Etnomatematika: Makanan Tradisional Bugis sebagai Sumber Belajar Matematika. MaPan, 7(2), 307-327. https://doi.org/10.24252/mapan.2019v7n2a10

Prahmana, R. C. I., \& D'Ambrosio, U. (2020). Learning Geometry and Values from Patterns: Ethnomathematics on the Batik Patterns of Yogyakarta, Indonesia. Journal on Mathematics Education, 11(3), 439-456. https://doi.org/10.22342/jme.11.3.12949.439456

Pusvita, Y., Herawati, \& Widada, W. (2019). Etnomatematika Kota Bengkulu: Eksplorasi Makanan Khas Kota Bengkulu “ Bay Tat.” 04(02), 185-193.

Putri, L. I. (2017). Eksplorasi Etnomatematika Kesenian Rebana sebagai Sumber Pembelajaran Matematika pada Jenjang MI. Jurnal Ilmiah PENDIDIKAN DASAR, IV(1), 21-31.

Siregar, N. R. (2017). Persepsi Siswa pada Pelajaran Matematika: Studi Pendahuluan pada Siswa yang Menyenangi Game. Prosiding Temu Ilmiah X Ikatan Psikologi Perkembangan Indonesia, 224-232.

Utami, R. N. F., Muhtadi, D., Ratnaningsih, N., Sukirwan, S., \& Hamid, H. (2020). Etnomatematika: Eksplorasi Candi Borobudur. JP3M (Jurnal Penelitian Pendidikan Dan Pengajaran Matematika), 6(1), 13-26. https://doi.org/10.37058/jp3m.v6i1.1438 